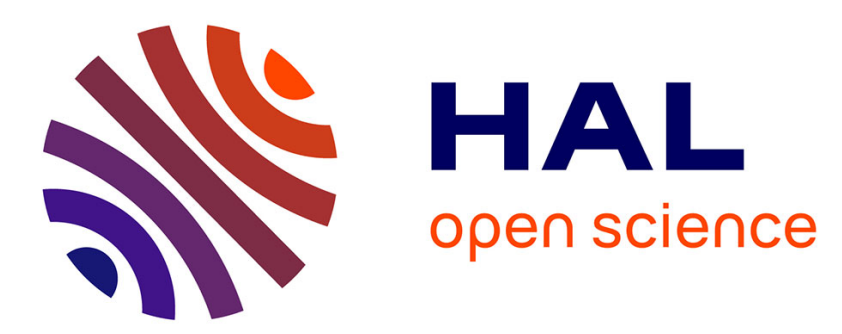

\title{
Energy management for hybrid energy storage systems: a comparison of current tracking control methods
}

\author{
Zhongliang Li, Seifeddine Ben Elghali, Rachid Outbib
}

\section{To cite this version:}

Zhongliang Li, Seifeddine Ben Elghali, Rachid Outbib. Energy management for hybrid energy storage systems: a comparison of current tracking control methods. IECON 2017 - 43rd Annual Conference of the IEEE Industrial Electronics Society, Oct 2017, Beijing, France. pp.7128-7133, 10.1109/IECON.2017.8217247 . hal-02476470

\section{HAL Id: hal-02476470 \\ https://hal.science/hal-02476470}

Submitted on 12 Feb 2020

HAL is a multi-disciplinary open access archive for the deposit and dissemination of scientific research documents, whether they are published or not. The documents may come from teaching and research institutions in France or abroad, or from public or private research centers.
L'archive ouverte pluridisciplinaire HAL, est destinée au dépôt et à la diffusion de documents scientifiques de niveau recherche, publiés ou non, émanant des établissements d'enseignement et de recherche français ou étrangers, des laboratoires publics ou privés. 


\title{
Energy management for hybrid energy storage systems: a comparison of current tracking control methods
}

\author{
Zhongliang Li, Seifeddine Ben Elghali, Rachid Outbib \\ Labratery LSIS (CNRS 7296) \\ Aix-Marseille University, Marseille, France \\ zhongliang.li@1sis.org, seifeddine.benelghali@1sis.org, rachid.outbib@lsis.org
}

\begin{abstract}
In order to correctly implement an energy management strategy for a multi-source system, the output currents of different sources should be regulated to the desired references precisely and rapidly. In this paper, the underlying control of hybrid energy storage system composed by battery and supercapacitor is presented. Three current tracking controllers, PID, sliding mode, and fuzzy logic, are designed for the proposed system. Then, the control performances of the three controllers are compared according to the control precision, feasible control parameter range, and robustness to input voltage variation. The comparison is realized by carrying out a series of simulations.
\end{abstract}

\section{INTRODUCTION}

Hybrid energy storage systems (HESSs) have been becoming more and more widely used in different kinds of electric vehicles (EVs). HESS composed by battery and supercapacitor (SC) ensures a longer life span of battery, higher efficiency and higher power density than using only battery as storage unit [1]. The battery/SC HESS has not only been used in EVs, but also found applications in renewable energy systems and in microgrids [2].

In a HESS, battery and SC are usually connected to the DC bus via DC/DC converters to obtain a controllable DC bus voltage. Thus, the control of HESS is realized by controlling these DC/DC converters. A number of studies are dedicated to new topologies and structures of DC/DC converters.

With a configured HESS, the energy management strategy (EMS) of the HESS is concerned. Most of the literature focused on the strategies by which the current references of different energy storage units are determined. Some strategies were proposed to maximize the system efficiency. While the others are dedicated to prolong the battery life span as possible. The multiple objectives can also be compromised and grouped into one objective function [3].

In most of the proposed EMSs, it is assumed that the current references generated by an EMS can be perfectly tracked by real output currents and the differences between the references and real outputs are usually neglected. However, the current tracking control of a HESS should be put more importance in consideration of the wide-range varied load, the different operating modes, the characteristics of different energy storage units and the interactions between different sources.

This paper is dedicated to the study of the underlying control, i.e. current tracking and DC bus voltage controls, of a HESS. With an identical EMS and voltage regulation method, three current tracking methods, PID control, sliding mode (SM) control and fuzzy logic (FL) control, are designed and compared. The evaluation of the control performances for the three controllers is based on control precision, feasible parameter range, and robustness to parameter uncertainty.

The paper is organized as follows: in Section II, the studied HESS is described and its model is provided. Section III is dedicated to the underlying control of the HESS. The design of voltage controller and three different current controls are respectively illustrated. Then, the EMS adopted in this study is provided and summarized in Section IV. The simulation results are shown in Section V and the comparison of the three current tracking controls is carried out in the same section. The study is finally concluded in Section VI

\section{SYSTEM DESCRIPTION AND MODELING}

The studied HESS consists of a battery and a SC and two DC/DC converters which connect the two energy storage units to the DC bus. As Fig. 1 shows, the upper IGBT of the battery side converter is disabled in our case, which makes the converter an unidirectional one, while the SC side converter is bidirectional. The battery and SC here are simply described by an ideal voltage source, a parasitic series resistance and a capacitor.

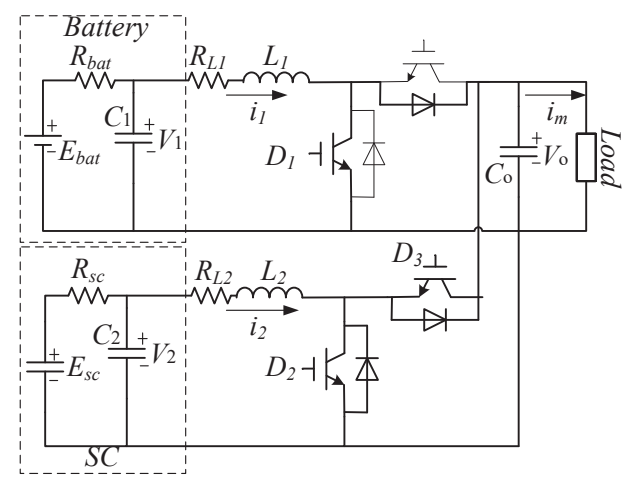

Fig. 1. System composed by battery and supercapacitor 
In [2], a 5-order average model of the is built, as

$$
\left\{\begin{array}{l}
\dot{x}=\left(A_{0}+A_{1} D_{1}+A_{2} D_{2}\right) x+B_{e} v_{e} \\
y=C x
\end{array}\right.
$$

where $x=\left[V_{1}, V_{2}, i_{1}, i_{2}, V_{o}\right]^{T}$. The meanings of the parameters are shown in Fig. 1.

$$
\begin{aligned}
& A_{11}=\left[\begin{array}{cc}
-\frac{1}{R_{b a t} C_{1}} & 0 \\
0 & -\frac{1}{R_{S C} C_{2}}
\end{array}\right], A_{12}=\left[\begin{array}{ccc}
-\frac{1}{C_{1}} & 0 & 0 \\
0 & -\frac{1}{C_{2}} & 0
\end{array}\right], \\
& A_{21}=\left[\begin{array}{cc}
\frac{1}{L_{1}} & 0 \\
0 & \frac{1}{L_{2}} \\
0 & 0
\end{array}\right] \\
& B_{e}=\left[\begin{array}{cc}
\frac{1}{R_{\text {bat }} C_{1}} & 0 \\
0 & \frac{1}{R_{S C} C_{2}} \\
0 & 0 \\
0 & 0 \\
0 & 0
\end{array}\right] \text {; } \\
& W_{0}=\left[\begin{array}{ccc}
-\frac{R_{L 1}+R_{o n 2}}{L_{1}} & 0 & -\frac{1}{L_{1}} \\
0 & -\frac{R_{L 2}+R_{o n 4}}{L_{2}} & -\frac{1}{L_{2}} \\
\frac{1}{C_{0}} & \frac{1}{C_{0}} & \frac{i_{m}}{V_{0} C_{0}}
\end{array}\right] \text {, } \\
& W_{1}=\left[\begin{array}{ccc}
\frac{R_{o n 2}-R_{o n 1}}{L_{1}} & 0 & \frac{1}{L_{1}} \\
0 & 0 & 0 \\
-\frac{1}{C_{0}} & 0 & 0
\end{array}\right] \\
& W_{2}=\left[\begin{array}{ccc}
0 & 0 & 0 \\
0 & \frac{R_{o n 4}-R_{o n 3}}{L_{2}} & \frac{1}{L_{2}} \\
0 & -\frac{1}{C_{0}} & 0
\end{array}\right] \\
& A_{0}=\left[\begin{array}{cc}
A_{11} & A_{12} \\
A_{21} & W_{0}
\end{array}\right], A_{1}=\left[\begin{array}{cc}
0 & 0 \\
0 & W_{1}
\end{array}\right], A_{2}=\left[\begin{array}{cc}
0 & 0 \\
0 & W_{2}
\end{array}\right] \text {; } \\
& V_{e}=\left[\begin{array}{l}
E_{b a t} \\
E_{S C}
\end{array}\right], C=\left[\begin{array}{lllll}
0 & 0 & 1 & 0 & 0 \\
0 & 0 & 0 & 1 & 0
\end{array}\right] \text {. }
\end{aligned}
$$

\section{CURREnt TRACKing AND DC VOlTAGE CONTROL}

The control of HESS can be separated into two phases. The first phase is the EMS through which the current references of the storage units are generated. Then, the references are exported to the second phase named current and voltage tracking phase, which is the concern of this paper.

To execute correctly the EMS, the current and voltage should be tracked precisely, rapidly, and stably. Here, the tracking control in HESS is regarded as a multi-input and multioutput nonlinear control problem. The control difficulties lie on three aspects: 1) The tracking control is subject to input saturation due to the limits on the duty cycles $\left(D_{1}, D_{2}\right.$ and $\left.D_{3}\right)$, which is normally within $[0,1]$. 2) Regarding the system model (1), the control inputs $D_{1}$ and $D_{2}$ are multiplied by the system states in the model, which means a bilinear term exists in the model. 3) The inputs are highly interacted, since the two converters are interconnected through the DC bus.

In the concerned control of HESS, the reference current of battery $\left(i_{L 1}^{r e f}\right)$ is generated through EMS. $i_{L 1}^{r e f}$ is tracked by regulating the battery side DC/DC converter. While the DC bus voltage is maintained by regulating the supercapacitor side converter. The DC voltage control also insures that the load power is compensated by SC. The flow chart of the tracking control is shown in Fig. 2. Note that in SC side control, a double-loop control frame is adopted. The outer loop is voltage loop from which the reference current of SC is generated. In the inner loop, the SC current is controlled by varying the duty cycle of the corresponding switches. The double-loop structure benefits the high stability and inductor current limitation and control [4].

In [5], it was shown that the time constant of voltage control loop is much longer than that of current loop. The voltage loop can be set by assuming that the current has been tracked to the desired value. It has been shown in the same study that a simple PI controller can insure the Lyapunov stability condition. In this study, a PI controller is used as the voltage loop controller.

$$
i_{\text {bat }}^{r e f}=k_{p, v}\left(V_{o}^{r e f}-V_{o}\right)+k_{i, v} \frac{\left(V_{o}^{r e f}-V_{o}\right)}{s}
$$

The more importance of this study is put on the design of current controller. Here, three emerging controllers are designed and compared in the perspectives of control performance, facility of parameter configuration, robustness.

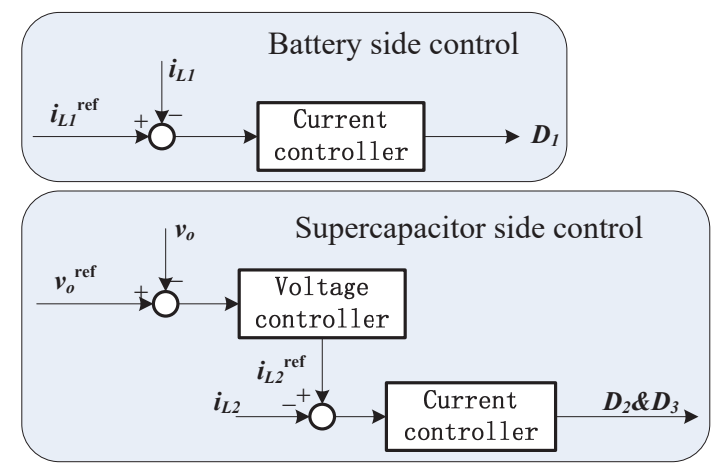

Fig. 2. Voltage and current tracking control flowchart

\section{A. PID control}

A proportional-integral-differential (PID) controller is usually considered for a traditional DC/DC converter control design. Although the effectiveness of PID has been validated in the current loop control of DC/DC converters, its performance in HESS should be evaluated since complex interactions exist in HESS. In addition, as a reference, PID control is compared to other emerging methods.

$$
\left[\begin{array}{l}
D_{1} \\
D_{2}
\end{array}\right]=\left[\begin{array}{l}
k_{p, b a t}\left(i_{b a t}^{r e f}-i_{1}\right)+k_{i, b a t} \frac{\left(i_{b a t}^{r e f}-i_{1}\right)}{s} \\
k_{p, S C}\left(i_{s c}^{r e f}-i_{2}\right)+k_{i, S C} \frac{\left(i_{s c}^{r e f}-i_{2}\right)}{s}
\end{array}\right]
$$

\section{B. Sliding mode control}

As a model based controller, the main advantages of SM control are mainly its stability and robustness against parameter uncertainties [6]. Moreover, the SM control method is relatively easy to implement when compared to some other nonlinear control methods.

In [5], the SM control is designed based on the model (1). In the controllers, the control outputs can be calculated as 


$$
\left[\begin{array}{c}
D_{1} \\
D_{2}
\end{array}\right]=\left[\begin{array}{l}
-\frac{V_{1}}{V_{o}}+i_{1} \frac{R_{L 1}+R_{o n 2}}{V_{o}}+1+k_{1} \frac{L_{1}}{V_{o}}\left(i_{\text {bat }}^{r e f}-i_{1}\right)+\varepsilon_{1} \frac{L_{1}}{V_{o}} \operatorname{sat}\left(i_{\text {bat }}^{\text {ref }}-i_{1}\right) \\
-\frac{V_{2}}{V_{o}}+i_{1} \frac{R_{L 2}+R_{o n 4}}{V_{o}}+1+k_{2} \frac{L_{2}}{V_{o}}\left(i_{s c}^{r e f}-i_{2}\right)+\varepsilon_{2} \frac{L_{2}}{V_{o}} \operatorname{sat}\left(i_{s c}^{r e f}-i_{2}\right)
\end{array}\right]
$$

where saturation function $\operatorname{sat}(S)$ is defined as

$$
\operatorname{sat}(S)=\left\{\begin{array}{l}
1 \quad S \in(1, \infty) \\
S \quad S \in[-1,1] \\
-1 \quad S \in(-\infty,-1)
\end{array}\right.
$$

\section{Fuzzy logic control}

Different from the model based control methods, FL control, known as a rule based controller, benefits several advantages such as robustness and model-free [7].

Taking the current control loop of battery side as example, the inputs of fuzzy controller are the error $e$ and the change of error de

$$
\left\{\begin{array}{l}
e=i_{b a t}^{r e f}-i_{1} \\
d e=e_{k}-e_{k-1}
\end{array}\right.
$$

where $k$ denotes the $k$ th control cycle. The values of $e$ and de are normalized before entering in the FL controller. The normalized values of $e^{*}$ and $d e^{*}$ are given by

$$
\left\{\begin{array}{l}
e^{*}=\beta_{e} e \\
d e^{*}=\beta_{d e} d e
\end{array}\right.
$$

where $\beta_{e}$ and $\beta_{d e}$ are respectively the normalized factors of $e^{*}$ and $d e^{*}$.

According to the input and output membership functions, predefined fuzzy rules and inference method, the relative change in the duty cycle $\delta D_{1}$ can be inferred, as

$$
\delta D_{1}=f\left(e^{*}, d e^{*}\right)
$$

where $f$ is imagined as the function corresponding to the concerned FL control.

The universe of $e^{*}$ and $d e^{*}$ are divided into seven fuzzy sets and shown in Fig. 3(a). Triangular membership functions, denoted by $\mu\left(e^{*}\right)$ and $\mu\left(d e^{*}\right)$, are used for fuzzy sets. Singleton membership function, denoted by $\mu(\delta D)$ is adopted as the output membership functions. The singletons are uniformly distributed within the domain of the fuzzy sets as shown in Fig. 3(b). The membership functions are defined with linguistic labels: Negative Big (NB), Negative Mean (NM), Negative Small (NS), Zero (ZE), Positive Small (PS), Positive Mean (PM) and Positive Big (PB), respectively. Note that for both input membership functions, the values of two parameters $p h$ and $p l$ can be set to achieve a satisfying performance.

To infer the output given an arbitrary inputs, Sugeno-Type fuzzy inference is adapted in this study. The inferred output $z_{i}$ of $i$ th active rule is written as

$$
z_{i}=\min \left\{\mu\left(e^{*}\right), \mu\left(d e^{*}\right)\right\} \cdot C_{i}=\omega_{i} \cdot C_{i}
$$

where $C_{i}$ is the output according to $i$ th rule.
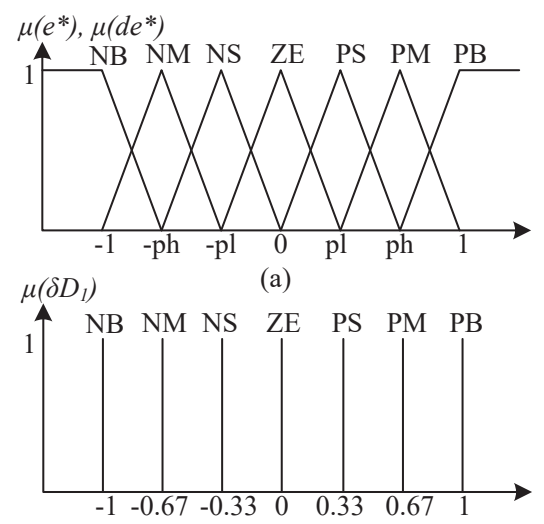

(b)

Fig. 3. Inputs membership and output membership

The final output of the system is the weighted average of all rule outputs, as

$$
\delta D_{1}=\frac{\sum_{i=1}^{N} C_{i} \cdot \omega_{i}}{\sum_{i=1}^{N} \omega_{i}}
$$

where $N$ is the number of the active rules.

TABLE I

FUZZY RULES

\begin{tabular}{cccccccc}
\hline & \multicolumn{7}{c}{$\delta D_{1}$} \\
$\downarrow$ & PB & PM & PS & ZE & NS & NM & NB \\
\hline PB & PB & PB & PB & PM & PM & PS & ZE \\
PM & PB & PB & PM & PM & PS & ZE & NS \\
PS & PB & PM & PM & PS & ZE & NS & NM \\
ZE & PM & PM & PS & ZE & NS & NM & NM \\
NS & PM & PS & ZE & NS & NM & NM & NB \\
NM & PS & ZE & NS & NM & NM & NB & NB \\
NB & ZE & NS & NM & NM & NB & NB & MB \\
\hline
\end{tabular}

\section{ENERGY MANAGEMENT METHOD}

EMS is not the main concern of this study. A simple rule based EMS approach used in the literature is selected and adopted in this study [5]. With the EMS, the reference current $i_{\text {bat }}^{r e f}$ of battery can be determined according to the load power and the voltage of supercapacitor. Specifically, as concluded in Algorithm 1, four modes are encountered in practice. When the supercapacitor voltage $\left(V_{S C}\right)$ is lower than the predefined threshold, 0.5 times full charged voltage $\left(V_{S C, \max }\right)$ in our case, the battery, whose output power is $P_{b a t}$, will provide the demanded load power $\left(P_{d e m}\right)$ and the power for charging the supercapacitor $\left(P_{c h g}\right)$. When the supercapacitor voltage is higher than the threshold and the load power is small $\left(P_{d e m}<\right.$ $\left.P_{\text {min }}\right)$, the battery will supply the demanded power and the output power of supercapacitor is idle. Otherwise, the battery 
will provide a constant power $\left(P_{\min }\right)$ and the supercapacitor compensate the rest demanded power.

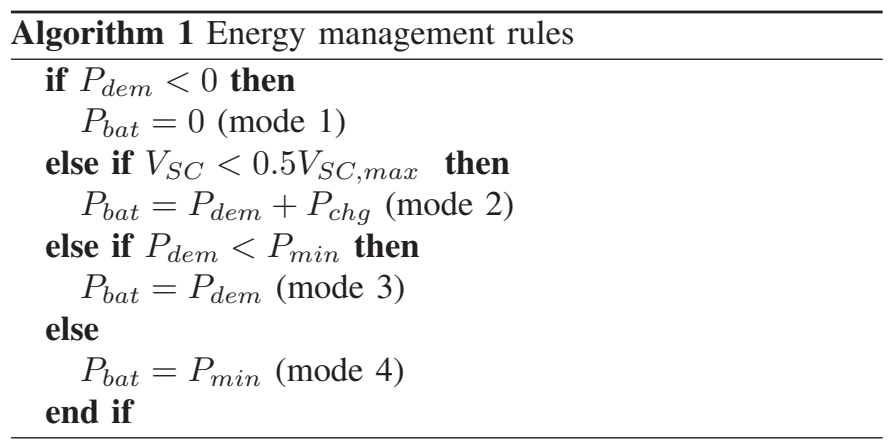

\section{Simulation Results AND Discussions}

\section{A. Simulation setting}

The parameters of the concerned HESS are summarized in Table II. The maximum output powers of battery and SC are $1260 \mathrm{~W}$ and $2688 \mathrm{~W}$.

The simulation can be carried out by using the average model (1) or using the Simpower models. With the same configuration of model and control parameters, the simulation results from the average model and Simpower model are shown in Fig. 4. It can be seen that consistent results can be obtained by using the two models. However, by using the average model, the simulation time can be much shortened. Hence, the following comparative study is based on the average model.

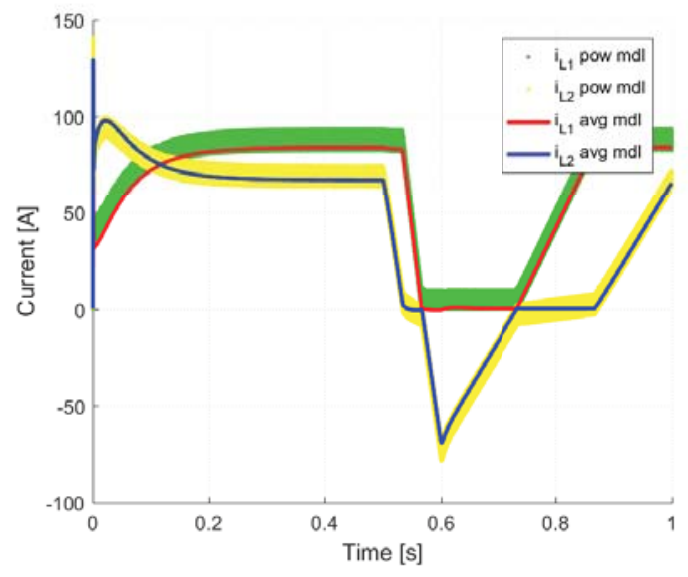

Fig. 4. Battery and supercapacitor output currents from Simpower model and average model. pow $\mathrm{mdl}$ denotes Simpower model, while avg $m d l$ denotes average model

In order to valuate the performance of the three controllers, the load power profile shown in Fig. 5 is proposed. In the profile, the processes of starting up, different operating modes, and the transitions between different modes and load levels are investigated.

Parameters of different controller are set in consideration of the control performance. To do so, integral absolute error
TABLE II

PARAMENTERS OF THE INVESTIGATED PLATEFORM

\begin{tabular}{cc}
\hline Parameter & Value \\
\hline Battery DC voltage $\left(E_{\text {bat }} / V\right)$ & 12 \\
Battery pack resistance $\left(R_{\text {bat }} / \Omega\right)$ & 0.01 \\
Battery side filter capacitance $\left(C_{1} / m F\right)$ & 69 \\
Battery side filter inductance $\left(L_{1} / \mu H\right)$ & 40.8 \\
Battery side inductor series resistance $\left(R_{1} / \Omega\right)$ & 0.001 \\
Load side capacitance $\left(C_{0} / m F\right)$ & 2.55 \\
Supercapacitor DC voltage $\left(E_{S C} / V\right)$ & 15 \\
Supercapacitor module resistance $\left(R_{S C} / \Omega\right)$ & 0.01 \\
Supercapacitor side filter capacitance $\left(C_{2} / \mu F\right)$ & 69 \\
Supercapacitor side filter inductance $\left(L_{2} / \mu H\right)$ & 50 \\
SC side inductor series resistance $\left(R_{2} / \Omega\right)$ & 0.001 \\
IGBT on resistance $\left(R_{\text {on }} / \Omega\right)$ & 0.001 \\
\hline Charged voltage of SC $\left(V_{S C, \max } / V\right)$ & 27 \\
Load power threshold $\left(P_{\min } / W\right)$ & 1000
\end{tabular}

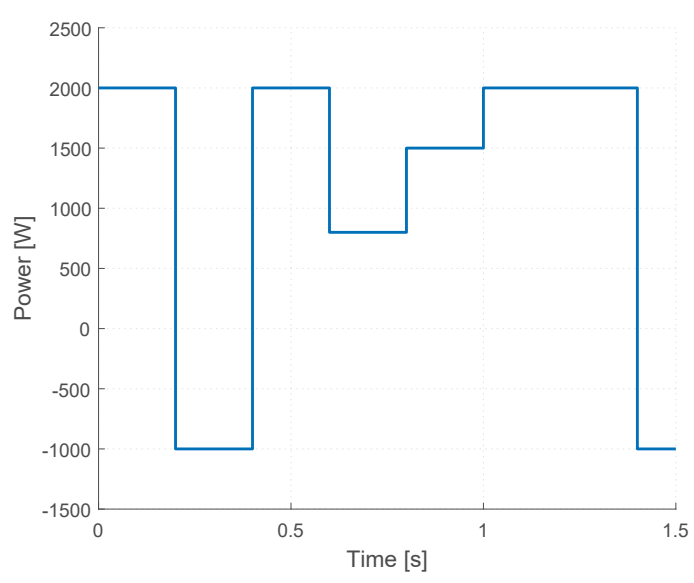

Fig. 5. Studied load power profile

(IAE) of the battery current control is defined to evaluate the control performance, as

$$
I A E=\int_{t=t_{0}}^{t_{l}}\left|i_{\text {bat }}^{\text {ref }}(t)-i_{1}(t)\right| d t
$$

where $t_{0}$ and $t_{l}$ are the beginning and end of the investigated process.

Here, the battery side and SC side current controllers are configured with the same parameters. For PID control and SM, two parameters are to be set for each. As for FL control, ph and $p l$ for membership function $\mu\left(e^{*}\right)$ and $\mu\left(d e^{*}\right)$ are to be set. Moreover, the normalized factors $\beta_{e}$ and $\beta_{d e}$ need to be set. In [7], to have a fast and precise response, $p h$ and $p l$ are set to be 0.3 and 0.15 for $\mu\left(e^{*}\right)$, and set to be 0.7 and 0.4 for $\beta_{d e}$. By using this configuration, two parameters $\beta_{e}$ and $\beta_{d e}$ of FL controller are left to set.

\section{B. Control precision}

For each controller, grid search method is adopted to find the optimal parameters which minimize $I A E$. The optimal parameters and the corresponding values of $I A E$ are collected in Table III. 


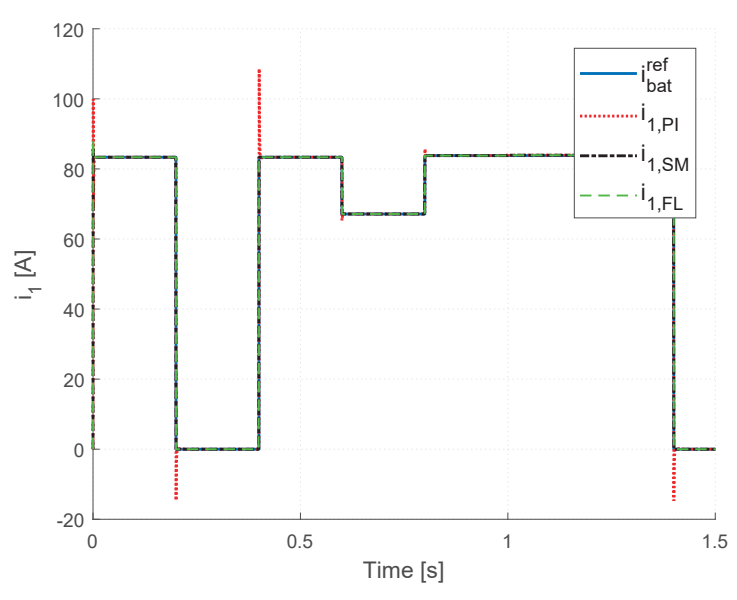

Fig. 6. Battery output current $i_{1}$ with different controllers.

From Table III, it can be seen that the value of $I A E$ by using PI controller is bigger than those by using SM and FL controllers. The minimized value $I A E$ is obtained by using SM controller, although it is only a little smaller than that by using FL controller.

TABLE III

INTEGRAL ABSOLUTE ERROR OF PID WITH DIFFERENT PARAMETERS

\begin{tabular}{cccc}
\hline Controller & Parameter & Value & $I A E$ \\
\hline \multirow{2}{*}{ PI } & $\begin{array}{c}k_{p, \text { bat }}, k_{p, S C} \\
k_{i, \text { bat }}, k_{i, \text { bat }}\end{array}$ & $\begin{array}{c}0.021 \\
30\end{array}$ & 0.1032 \\
& $k_{1}, k_{2}$ & 0.5 & 0.0362 \\
\multirow{2}{*}{$\mathrm{SM}$} & $\varepsilon_{1}, \varepsilon_{2}$ & 0.22 & \\
& $\beta_{e}$ & 2 & 0.0376 \\
\multirow{2}{*}{$\mathrm{FL}$} & $\beta_{d e}$ & 1 & \\
\hline
\end{tabular}

The reference battery current $i_{\text {bat }}^{\text {ref }}$ and the measured output currents by using different controllers are shown in Fig. 6. Evident overshoots can be observed in the transition periods with PI control, while for the other two controls, no obvious overshoots can be observed. Some details of the system starting up process is shown in Fig. 7(a), while a transition process in $0.8 \mathrm{~s}$ is shown in Fig. 7(b). From Fig. 7(a), SM control has acquired the fastest starting up process with the smallest overshoot, while PID control performs worst in the two aspects. In Fig. 7(b), the performance of SM and FL controls can be further compared. For SM control, only two control periods are taken to reach the reference current. For FL control, more time is needed to reach the objective in this transition process.

\section{Feasible control parameter range}

In practice, it is hoped that the control performance could be maintained acceptable in a wide range of control parameters. This benefits not only an easier parameter tuning stage, but also a more robust control versus parameter uncertainty.

The value of $I A E$ is calculated by varying control parameters to 0.1 and 10 times the optimal values. The results of the three concerned controls are collected respectively in Table (a)

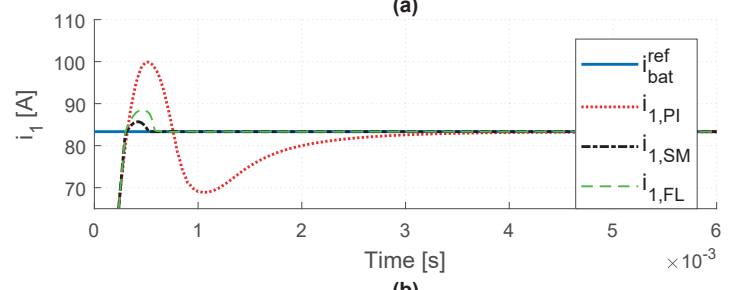

(b)

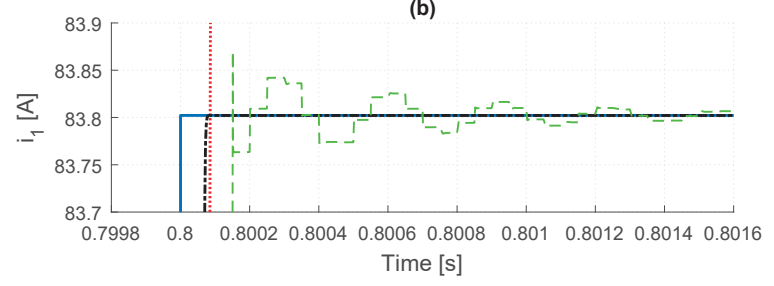

Fig. 7. Battery output current details

IV, V and VI. From the three tables, the range of feasible parameters for PI controller is relatively narrow. When the optimal parameters are increased or decreased by 10 times, the performance is degenerated significantly. Regarding SM and FL controls (see Table V and VI), the control performance is maintained at a high level.

TABLE IV

INTEGRAL ABSOLUTE ERROR OF PID WITH DIFFERENT PARAMETERS

\begin{tabular}{cccc}
\hline IAE & $0.1 K_{p, o p t}$ & $K_{p, o p t}$ & $10 K_{p, o p t}$ \\
\hline $0.1 K_{i, o p t}$ & 0.6027 & 0.3758 & 124.7 \\
$K_{i, o p t}$ & 791.4 & $\mathbf{0 . 1 0 3 2}$ & 123.9 \\
$10 K_{i, o p t}$ & 1175 & 601.0 & 123.1 \\
\hline
\end{tabular}

TABLE V

INTEGRAL ABSOLUTE ERROR OF SMC WITH DIFFERENT PARAMETERS

\begin{tabular}{cccc}
\hline IAE & $0.1 k_{\text {opt }}$ & $k_{\text {opt }}$ & $10 k_{\text {opt }}$ \\
\hline $0.1 \varepsilon_{\text {opt }}$ & 0.0371 & 0.0362 & 0.0368 \\
$\varepsilon_{\text {opt }}$ & 0.0369 & $\mathbf{0 . 0 3 6 2}$ & 0.0368 \\
$10 \varepsilon_{\text {opt }}$ & 0.0363 & 0.0363 & 0.0369 \\
\hline
\end{tabular}

TABLE VI

INTEGRAL ABSOLUTE ERROR OF FLC WITH DIFFERENT PARAMETERS

\begin{tabular}{cccc}
\hline IAE & $0.1 \beta_{e, o p t}$ & $\beta_{e, o p t}$ & $10 \beta_{e, o p t}$ \\
\hline $0.1 \beta_{\text {de,opt }}$ & 0.0384 & 0.0385 & 0.0392 \\
$\beta_{\text {de,opt }}$ & 0.0393 & $\mathbf{0 . 0 3 7 6}$ & 0.0381 \\
$10 \beta_{\text {de,opt }}$ & 0.0462 & 0.0377 & 0.0381 \\
\hline
\end{tabular}

\section{Robustness to input voltage variation}

In model (1), it is assumed that the states of charge, i.e. $E_{b a t}$ and $E_{S C}$, are constant since the variation of these variables can be neglected in a control period or switching period. In this study, in order to compare the robustness of different current tracking controllers, the $E_{b a t}$ and $E_{S C}$ are considered to be varied during the simulation. In fact, with a constant $E_{b a t}$ and 
$E_{S C}$, the control outputs, i.e. $D_{1}$ and $D_{2}$, are maintained at the same level. The variation of $E_{b a t}$ and $E_{S C}$ can result in the variation of control outputs. Thus, the control performance of different operating points with respect to duty cycle can be investigated. In addition, the effect of model uncertainty of battery and SC can be imitated by varying $E_{b a t}$ and $E_{S C}$.

Here, $E_{b a t}$ and $E_{S C}$ are assumed to evolve as shown in Fig. 8. The same load power profile is used in the simulation. The battery currents with different control methods are shown in Fig. 9. Similar as the previous simulation result, the overshoots by using PI control are obvious in the transitions, $0.15 \mathrm{~s}, 0.3 \mathrm{~s}$ for instance. While no evident overshoot is observed using the other two controller. The values of $I A E$ are respectively $0.1790,0.0532,0.0548$ by using PI, SM, FL controllers.

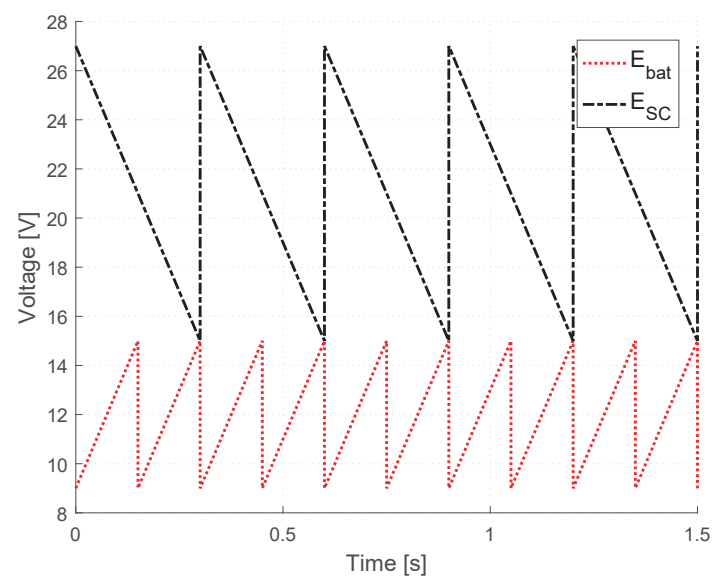

Fig. 8. Evolutions of $E_{b a t}$ and $E_{S C}$

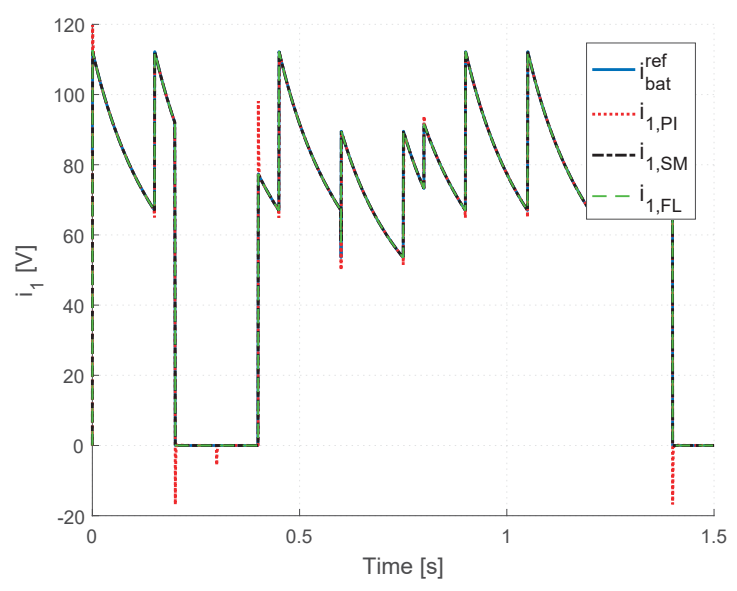

Fig. 9. Battery output currents $i_{1}$ with input voltage disturbance

The DC bus voltage $V_{o}$ is shown in Fig. 10. Since the time constant of current control loop is much shorter than that of voltage control loop, the voltage control performance is mainly determined by the voltage controller, which is identical in the

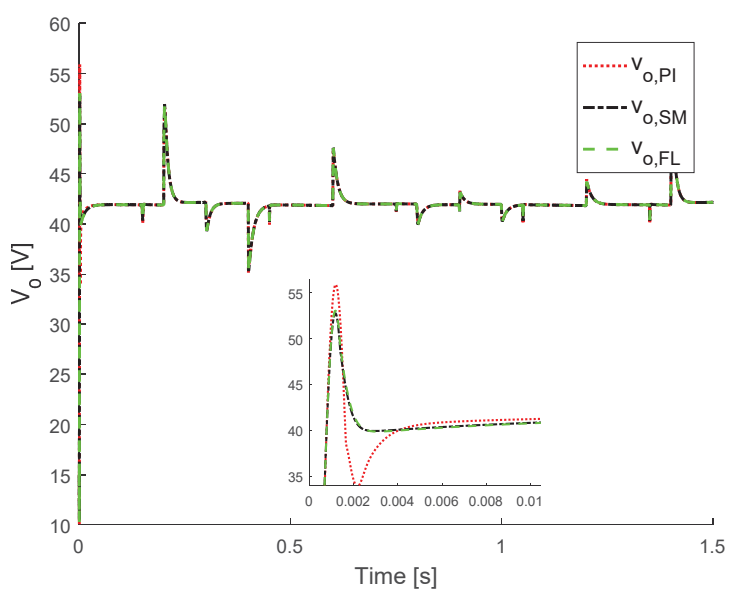

Fig. 10. DC bus voltage $v_{o}$ with input voltage disturbance

study. From Fig. 10, it can be seen that the responses of $V_{o}$ are similar in the three cases. Exceptionally, in the starting up stage, the response by using PI current controller is slower and the overshoot is bigger than the other two.

\section{CONCLUSION}

The paper focuses on the underling control of HESS. Specifically, three classical current controllers, PI, SM, and FL controllers, are compared from the perspectives of control precision, feasible parameter range, and robust to input voltage variation. From the simulation results, the performances of SM and FL are obviously better than PI control in the three aspects. Between SM and FL, SM performs slightly better than FL regarding the control precision. However, that FL is independent of model makes it also a good choice in practice.

\section{REFERENCES}

[1] M. B. Camara, B. Dakyo, and H. Gualous, "Polynomial Control Method of DC / DC Converters for DC-Bus Voltage and Currents Management Battery and Supercapacitors," IEEE Transactions on Power Electronics, vol. 27, no. 3, pp. 1455-1467, 2012.

[2] H. Jung, H. Wang, and T. Hu, "Control design for robust tracking and smooth transition in power systems with battery/supercapacitor hybrid energy storage devices," Journal of Power Sources, vol. 267, pp. 566575, 2014.

[3] B. Wang, J. Xu, B. Cao, and X. Zhou, "A novel multimode hybrid energy storage system and its energy management strategy for electric vehicles," Journal of Power Sources, vol. 281, pp. 432-443, 2015.

[4] Z. Chen, "Double loop control of buck-boost converters for wide range of load resistance and reference voltage," IET Control Theory \& Applications, vol. 6, no. 7, p. 900, 2012.

[5] Z. Song, J. Hou, H. Hofmann, J. Li, and M. Ouyang, "Sliding-mode and lyapunov function-based control for battery/supercapacitor hybrid energy storage system used in electric vehicles," Energy, vol. 122, pp. $601-612$, 2017.

[6] C. K. T. Siew-Chong Tan, Yuk-Ming Lai, Sliding Mode Control of Switching Power Converters. CRC Press, 2012.

[7] J. Solano-Martinez, H. D., and M.-C. Péra, "Type-2 fuzzy logic control of a DC/DC buck converter," Power Plants and Power Systems Control, vol. 8, no. 1, pp. 103-108, 2012. 